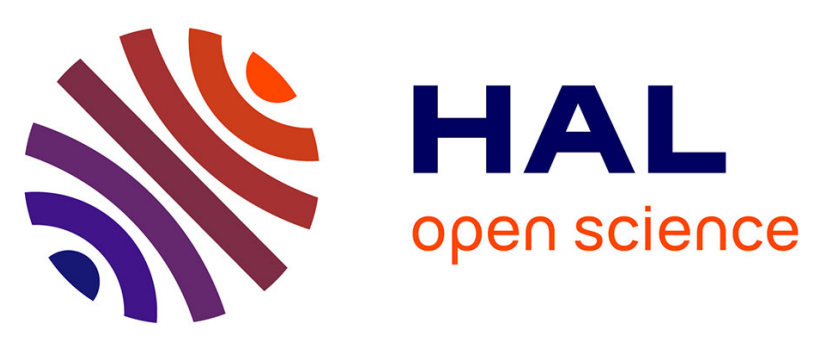

\title{
Monoclonal Antibodies Targeting the IL-17/IL-17RA Axis: An Opportunity to Improve the Efficiency of Anti-VEGF Therapy in Fighting Metastatic Colorectal Cancer?
}

\author{
Sajida Ibrahim, Alban Girault, Marc Ohresser, Emilie Lereclus, Gilles \\ Paintaud, Thierry Lecomte, William Raoul
}

\section{To cite this version:}

Sajida Ibrahim, Alban Girault, Marc Ohresser, Emilie Lereclus, Gilles Paintaud, et al.. Monoclonal Antibodies Targeting the IL-17/IL-17RA Axis: An Opportunity to Improve the Efficiency of Anti-VEGF Therapy in Fighting Metastatic Colorectal Cancer?. Clinical Colorectal Cancer, 2017, 10.1016/j.clcc.2017.10.003 . inserm-01661759

HAL Id: inserm-01661759

https://www.hal.inserm.fr/inserm-01661759

Submitted on 12 Dec 2017

HAL is a multi-disciplinary open access archive for the deposit and dissemination of scientific research documents, whether they are published or not. The documents may come from teaching and research institutions in France or abroad, or from public or private research centers.
L'archive ouverte pluridisciplinaire HAL, est destinée au dépôt et à la diffusion de documents scientifiques de niveau recherche, publiés ou non, émanant des établissements d'enseignement et de recherche français ou étrangers, des laboratoires publics ou privés. 
Monoclonal antibodies targeting IL-17/IL-17RA axis: an opportunity to improve the efficiency of anti-VEGF therapy in fighting metastatic colorectal cancer?

Sajida Ibrahim ${ }^{1}$, Alban Girault ${ }^{1}$, Marc Ohresser ${ }^{1}$, Emilie Lereclus ${ }^{1}$, Gilles Paintaud ${ }^{1,3}$, Thierry Lecomte $^{1,2}$ and William Raoul ${ }^{1}$

${ }^{1}$ Université François-Rabelais de Tours, CNRS, GICC UMR 7292, Tours, France

${ }^{2}$ CHRU de Tours, Department of Hepato-Gastroenterology and Digestive Oncology, Tours, France

${ }^{3}$ CHRU de Tours, Laboratory of Pharmacology-Toxicology, Tours, France

\section{Corresponding author}

Dr William RAOUL

CNRS UMR 7292 / GICC - UFR de médecine - BP 3223

10, boulevard Tonnellé 37032 TOURS Cedex 01, FRANCE

Tel: +3324736 6267 / Fax: +33247366125

E-mail: william.raoul@univ-tours.fr

\section{KEYWORDS}

Colorectal cancer; Monoclonal antibodies; Immunotherapy; Vascular endothelial growth factor; Interleukin-17; Mechanisms of resistance; Polymorphisms 


\section{CORE TIP}

Therapeutic monoclonal antibodies against VEGF have recently emerged as essential biopharmaceuticals for the advanced stages of colorectal cancer. Unfortunately, after an initial benefit for the patients, resistance invariably develops. Recent publications indicate that IL-17/IL-17RA axis could be a key player in the pathological progression. We here present evidence for IL-17 targeting in metastatic colorectal cancer in order to improve efficiency of anti-VEGF-based therapy and to implement new therapeutic avenues.

\section{ABSTRACT}

Colorectal cancer is a major problem for public health worldwide because of its frequency and its severity. Many efforts have been carried to target VEGF pathway, one of the main promoters of pathological angiogenesis. Therapeutic monoclonal antibodies against VEGF have emerged as essential biopharmaceuticals for the advanced stages of the disease, in association with appropriate backbone chemotherapy. Unfortunately, after an initial benefit for the patients, resistance invariably develops. These mechanisms of resistance are largely studied and recent publications indicate that IL-17/IL-17RA axis could be a key player in the pathological progression. In this mini-review, we will present evidence for IL-17A/IL-17RA axis targeting in colorectal cancer in order to improve efficiency of anti-VEGF therapy and to implement new therapeutic strategy. 


\section{INTRODUCTION}

Colorectal cancer (CRC) is a major problem for public health around the world because of its frequency and its severity ${ }^{1,2,3}$. CRC is the $2^{\text {nd }}$ cause of cancer related death in Europe and in USA and the $3^{\text {rd }}$ cause worldwide. The majority of death is due to metastases, which are mainly located in the liver. About $90 \%$ of new cases and deaths occur in individuals aged 50 years and older.

The understanding of signaling pathways and their molecular mechanisms in CRC allowed the development of targeted therapies besides conventional chemotherapy ${ }^{4}$. To date, a total of four monoclonal antibodies (mAbs), one fusion protein and one tyrosine kinase inhibitor are approved by US Food and Drug Administration (FDA) and European Medicines Agency (EMA) to fight against metastatic colorectal cancer (mCRC) when associated with appropriate backbone chemotherapy:

- mAbs targeting epidermal Growth Factor receptor (EGFR) mAbs: cetuximab $\left(\right.$ Erbitux $\left.^{\circledR}\right)$ and panitumumab (Vectibix $\left.{ }^{\circledR}\right)$.

- mAbs targeting vascular endothelial growth factor (VEGF) and its receptor VEGFreceptor 2 (VEGF-R2): bevacizumab (Avastin ${ }^{\circledR}$ ) and ramucirumab (Cyramza ${ }^{\circledR}$ ), respectively.

- A fusion protein targeting VEGF-A, VEGF-B and placental growth factor: VEGFtrap/aflibercept (Zaltrap $\left.{ }^{\circledR}\right)$.

- Tyrosine kinase inhibitor of VEGF signaling pathways: regorafenib (Stivarga ${ }^{\circledR}$ ).

Since VEGF/VEGFR2 is a key signaling pathway implicated in angiogenesis, anti-VEGF therapies, primarily directed against endothelial cells, have been assumed to be very promising in cancer treatment and to present a low risk of resistance ${ }^{5}$. Despite the initial efficacy of drugs targeting tumor angiogenesis in $\mathrm{mCRC}$, resistance invariably develops $6,7,8$. Both in vitro and in vivo studies were carried to understand the resistance to anti-VEGFs. For instance, Fan et al. showed that chronic exposure of CRC cell lines to bevacizumab resulted in increased expression of VEGF family members, and those cells were found to be more aggressive when injected into mice ${ }^{9}$. Furthermore, prolonged inhibition of VEGF in CRC cell lines caused a resistance to hypoxia-induced apoptosis and an increase of VEGF expression level ${ }^{10}$. Moreover, Mésange et al. reported that intrinsic resistance to bevacizumab was accompanied by high levels of VEGF in the tumor microenvironment of xenografted mice. In 
the same report, the authors also demonstrated that this resistance is accompanied with an activation of hypoxia inducible factor (HIF), VEGF-R1 and VEGF-R2 signaling in the tumor cells, and a resistance to hypoxia-induced apoptosis ${ }^{11}$.

Resistance to drugs targeting tumor angiogenesis in $\mathrm{MCRC}$ is at the forefront of research. Multiple molecular mechanisms of resistance have been identified. One is the activation of alternative signaling of key downstream pathways despite sustained inhibition of the original drug target. Interestingly, increasing evidence suggests that resistance to anti-VEGF therapies could be partly due to IL-17/IL-17 receptor A (IL-17RA) axis. In this mini-review, we will present evidence for targeting IL-17/IL-17RA axis in $\mathrm{MCRC}$ to improve current therapies.

\section{IL-17 A NEW PLAYER IN COLORECTAL CANCER DEVELOPMENT}

\section{IL-17 family: a rapid overview}

IL-17 family is already well-known ${ }^{12}$. Briefly, IL-17A, the most studied ligand of this family, is a pro-inflammatory cytokine that contributes to the pathogenesis of inflammatory and autoimmune diseases ${ }^{13,14}$. This soluble factor is also highly associated with cancer progression ${ }^{15}$, 16. A canonical source of IL-17A is a lineage of T cells known as CD4 ${ }^{+}$T helper Th17 cells ${ }^{17}$. TGF-beta, IL-6, IL-21 and other factors usually released in the tumor microenvironment are responsible for the induction of Th17 differentiation and IL-23 contributes to sustain the Th17 phenotype. In these cells the production of IL-17A is regulated by transcription factor ROR $\gamma \mathrm{t}$ (ROR is retinoic orphan receptor) which in turn is induced by STAT3 ${ }^{18}$. IL-17A is also secreted by lymphocytes NKT-17, $\gamma \delta \mathrm{T}-17, \mathrm{CD} 8^{+} \mathrm{Tc} 17$, polymorphonuclear neutrophils and intestinal Paneth cells 19,20. IL-17A homodimers bind to the complex formed by IL-17 Receptor (R)A/IL-17RC heterodimer. Interleukin-17 F (IL-17F) is a recently described member of the IL-17 family with a great homology to IL-17A. IL-17F is mainly secreted by $\mathrm{CD} 4^{+} \mathrm{T}$ cells and $\gamma \delta \mathrm{T}-17$ lymphocytes and acts as homodimer or as heterodimer with IL-17A ${ }^{21}$. Its signaling occurs through the same receptors as IL-17A, with a better affinity to IL17RC ${ }^{19}$.

\section{IL-17A: a possible prognosis factor}

Strong evidence supports the implication of IL-17 and its downstream signaling in the initiation and progression of CRC. However, the underlying mechanism remains unclear. 
Previously, Le Gouvello and colleagues ${ }^{22}$ have demonstrated an increase of IL-17A intratumor expression in proficient mismatch repair colon cancer (Microsatellite Stability, MSS, poor prognosis phenotype), to which belong the majority of CRCs ${ }^{23}, 24$. IL-17A expression level was found to be significantly elevated in the tumor environment of CRC from the adenoma stage to the cancer stage ${ }^{25}$. It was also suggested that high IL-17A tissue expression level could be associated with the aggressiveness of CRC and with poor prognosis ${ }^{26}$. In addition, serum levels of IL-17A were found to be increased in CRC patients ${ }^{27,28}$ and high baseline IL-17A serum concentrations may be associated with shorter progression-free survival in patients with metastatic colorectal cancer treated with a bevacizumab-based chemotherapy ${ }^{29}$. Interestingly, this is accompanied by an increased percentage of Th17 cells in the circulation in early stages of CRC, whereas in advanced stages those cells would rather infiltrate and accumulate in tumor tissue ${ }^{28}$. Moreover, CRC patients with low level of IL-17A present a higher 5-year survival rate compared to those with a high level suggesting that the expression level of IL- 17A can predict the poor prognosis of human CRC ${ }^{26}$. A clinical study reveals that high Th17 signature (expression of Th17 clusters of genes IL-17A, RORC) in patients with stage I or II of CRC reduces disease-free survival after resection of primary tumors ${ }^{30}$. Nevertheless, the tumorigenic role of IL-17A in CRC is not only accomplished by Th17-derived IL-17A. This has been recently proved in a murine study where a critical tumorigenic requirement for IL-17A generated mainly by $\gamma \delta \mathrm{T}$ cells (and other sources) was reported in mice carrying Enterotoxigenic Bacteroides fragilis tumor ${ }^{31}$. Tseng et al. reported a positive correlation between the serum level of IL-17A and circulating tumor cells (CTCS) known to cause metastasis, both in CRC patients and mice ${ }^{32}$. Furthermore, in the same report, IL17-A depletion with intraperitoneal injection of anti-IL-17A monoclonal antibody in mice suppressed the increase of CTCs and prevented metastasis ${ }^{32}$. Taken together, these data suggest that IL-17A could serve as a prognostic marker and a therapeutic target for CRC metastasis.

\section{Mechanisms of action of IL-17 in tumorigenesis and resistance to anti-VEGF treatment}

An elegant study reported that one of the mechanisms of IL-17A promoting tumorigenesis is exerted by IL-17RA engagement in colonic epithelial cells. Indeed, IL-17RA activates ERK, p38 MAPK, and NF-KB signaling pathways within transformed enterocytes and promotes their 
proliferation in a mice model causing early tumor development ${ }^{33}$. The pro-tumoral role of IL17A is also relying on the surrounding stromal cells. In murine models, Chung and colleagues showed that tumor infiltrating Th17 cells and IL-17 can activate tumor-associated fibroblasts (TAF) to secrete granulocyte colony-stimulating factor (G-CSF), which in turn recruits myeloid-derived suppressive cells (MDSC) to the tumor micro-environment ${ }^{34}$. More precisely, these MDSC ${ }^{35}$ produce angiogenic and immune-suppressive molecules such as VEGF, prokineticin 2/Bv8, matrix metalloproteinase-9 (MMP9) and pro-inflammatory S100A8/9 molecules (calprotectin), thereby mediating resistance to anti-VEGF treatment ${ }^{34}$.

Recruited by Th17 lymphocytes, MDSCs could also lead to a feed-forward effect (loop) by promoting Th17 differentiation and IL-17A production ${ }^{36}$. Notably, MDSCs were found to be crucial for the development of Th17 through the production of IL-1 $\beta$, IL-6, IL-23, and nitric oxide (NO) in patients with ovarian cancer ${ }^{37}$.

Besides, the inflammatory responses driven by IL-17A were proved to be increased in human CRC tissues which show the highest levels of this cytokine comparing to adenoma and normal tissues. This was highlighted by the activation of extracellular signal-regulated kinase (ERK)1/2 and C-Jun N-terminal kinase (JNK) pathways and the increased expression of matrix metalloproteinases (MMP9, MMP7, and MMP2), B-cell lymphoma (Bcl-2) and cyclin D1 ${ }^{38}$.

Moreover, IL-17 promotes tumorigenesis indirectly by inducing IL-6 production by tumor and surrounding stromal cells (mainly fibroblasts and endothelial cells) which activates STAT3, an oncogenic signal transducer and activator of transcription, resulting in up-regulation of survival and proangiogenic genes ${ }^{39}$. Further, a significant correlation between intra-tumor expression of IL-17 and VEGF has been reported using immuno-histochemical staining of tissues from 52 CRC patients ${ }^{26}$. These studies confirm the proangiogenic role of IL-17A showed for the first time by Numasaki et al. who indicated that locally secreted IL-17 by tumors promotes angiogenesis and thereby enhances tumor growth in mice models ${ }^{40} . \mathrm{A}$ recent study has shown that a membrane bound form of IL-17A expressed in a CRC cell line (CT26), which binds strongly and stably to the IL-17A receptor, enhances cell cycle progression and tumorigenesis ${ }^{41}$.

The mechanisms of action of IL-17A described above are illustrated in figure 1. 


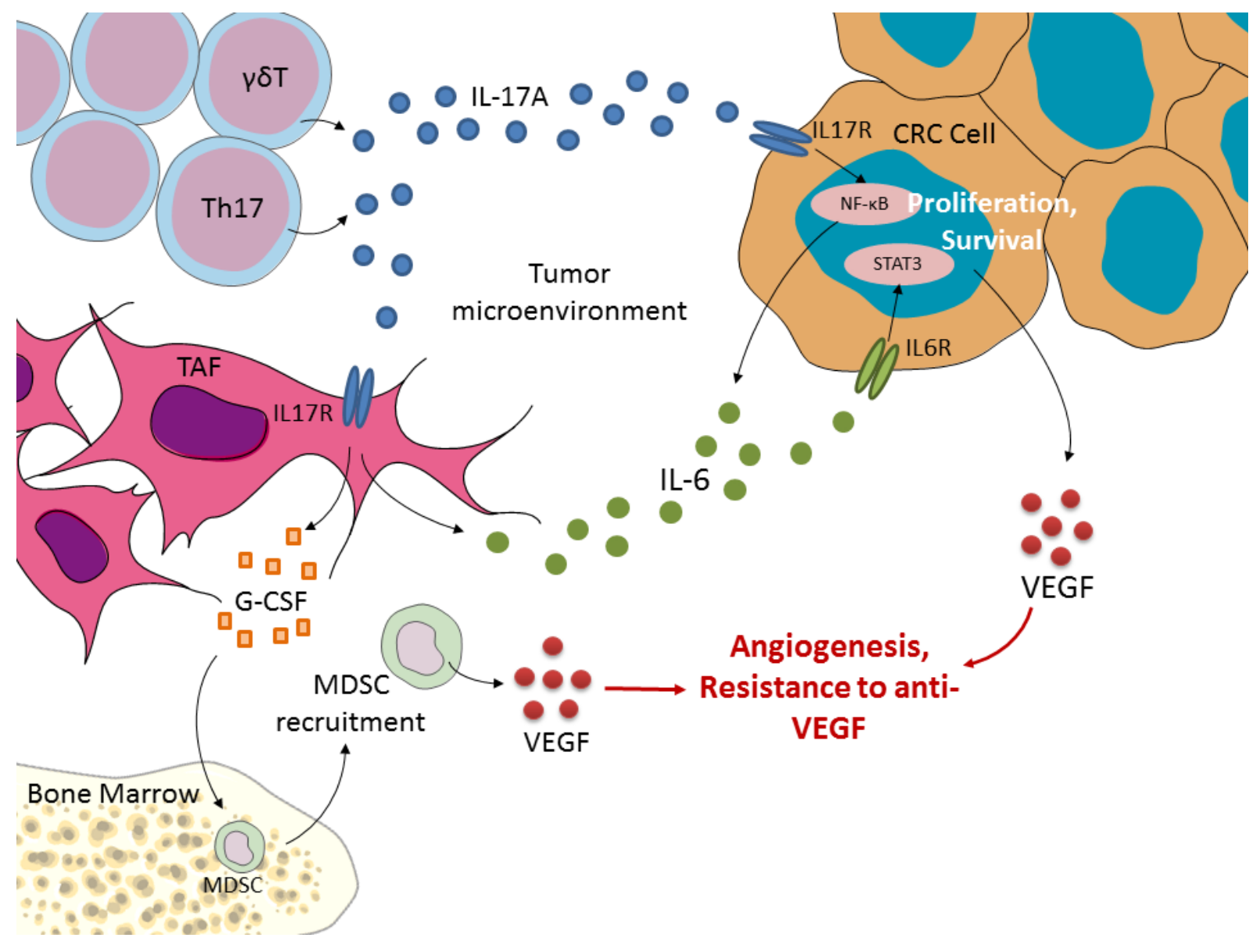

Figure 1. Schematic diagram showing the implication of IL-17A in tumorigenesis and resistance to anti-VEGF therapies in colorectal cancer. Abbreviations: CRC: Colorectal cancer; TAF: Tumor-associated fibroblast; STAT3: Signal transducer and activator of transcription 3; NF-kB: nuclear factor-kappa B; MDSC: Myeloid-derived suppressor cells; GCSF: Granulocytes colony-stimulating factor; VEGF: Vascular endothelial growth factor.

\section{II-17 axis, the anti-tumoral side}

Despite the strong evidence of IL-17A pro-tumoral role, an anti-tumoral side of IL-17A was reported in some studies. Interestingly, gastric adenocarcinoma patients with high IL-17 intra-tumoral expression showed a significantly higher five-year survival rates than those with lower IL-17 expression ${ }^{42}$. Moreover, II-17 participates in the reduction of both tumor growth and metastasis in a syngeneic MC38 colorectal cancer model ${ }^{43}$. The anti-tumor function of IL-17 is generated by enhancing natural killer cells and cytotoxic T lymphocytes activation, mainly through the recruitment of neutrophils, NK cells and T cells to tumor. These anti-tumoral mechanisms have already been nicely reviewed elsewhere ${ }^{44,18}$. It worth 
noting that IL-17F is reported to exert an anticancer effect ${ }^{45}$. Interestingly, it was shown that IL-17F is down-regulated throughout tumorigenesis in human CRC tissues and its expression is suppressed CRC tumor progression in mice ${ }^{46}$.

An explanation of the different functions and amounts of IL-17A and IL-17F in the tumor milieu could be partly attributable to the high plasticity of their main producer, the Th17 cell lineage that has quite recently broken the Th1/Th2 paradigm. The dynamic balance between Th17 and Th1 or between Th17 and T regulatory (Treg) cells is crucial for tumor progression/regression and depends on local onco-inflammatory stimuli and cell-cell interactions. These $\mathrm{CD}^{+}$lineages are especially subject to reciprocal transdifferentiation or reverse plasticity. The review by Ye et al. emphasizes characteristics of Th17 plasticity and Th17 heterogeneity in tumor immunity ${ }^{47}$.

\section{Implication of the polymorphisms of IL-17}

The effect of single nucleotide polymorphisms (SNPs) of IL-17A gene on inflammatory bowel diseases risk has been shown in several studies ${ }^{45,46}$. Moreover, ulcerative colitis has been associated with subsequent development of CRC ${ }^{50}$. This suggested the possible implication of IL-17A polymorphisms in CRC risk. Many studies and meta analysis have been carried to clarify the effects of IL-17A G197A (rs2275913) and IL-17F T7488C (rs763780) polymorphisms on cancer risk. The rs2275913 polymorphism correlates with more efficient IL-17A secretion and enhances IL-17-mediated immune responses 51 while the rs763780 polymorphism causes a Histidine-to-Arginine substitution at amino acid 161 (H161R) which antagonizes the function of wild-type IL-17F ${ }^{52}$. These polymorphisms may be relevant for digestive cancers since several studies reported an association between $I L-17$ polymorphisms and an increased risk of gastric cancer ${ }^{53-56}$. Dai et al. showed in a meta-analysis that both of IL-17A rs2275913 and $I L-17 F$ rs 763780 polymorphisms increase the risk of cancer development ${ }^{57}$. Iranian ${ }^{58}$ and Tunisian ${ }^{59}$ case-control studies showed that IL-17A polymorphisms were associated with increased risk of CRC development. A recent meta-analysis showed the association of the IL-17A polymorphisms with an increased risk of cancer in Asian populations, especially cervical cancer, breast cancer, and ovarian cancer ${ }^{60}$. Few data exist from patients in Europe or in Western countries on the association of these polymorphisms with the risk of CRC. 
Hence, more studies are needed to clarify whether IL-17A polymorphisms might be used as a diagnostic biomarker of CRC regarding ethnicities.

\section{MONOCLONAL ANTIBODIES TARGETING IL-17/IL-17RA AXIS}

All the proofs described above make II-17A one the most promising targets in CRC. But for now therapeutic biopharmaceuticals inhibiting IL-17 signaling are only developed and investigated in immune-mediated disorders (inflammatory and autoimmune diseases) such as psoriasis ${ }^{61}$ and rheumatoid arthritis ${ }^{62}$.

Currently, three biologic agents targeting IL-17/IL-17RA axis are studied and successfully passed phase 3 clinical trials: secukinumab, ixekizumab and brodalumab. The different mAbs targeting II-17/II-17RA axis and their main characteristics are shown in table 1.

Secukinumab (Cosenty $x^{\circledR}$ ), also known as AIN457, is a fully human IgG1k monoclonal antibody targeting IL-17A ${ }^{63}$. It is the first anti-IL-17A approved by FDA for the treatment of moderate to severe plaque psoriasis, psoriatic arthritis, and ankylosing spondylitis and administered by subcutaneous injection. Ixekizumab $\left(\operatorname{Tal}^{\circledR}\right)$ is a humanized IgG4 monoclonal antibody neutralizing IL-17A. It has been approved by FDA and EMA for the treatment of plaque psoriasis (phase III clinical trials) ${ }^{64}$. Finally, brodalumab (Lumice ${ }^{\circledR}$ ) is a fully human IgG2 monoclonal antibody that binds with high affinity to IL-17RA and thereby it blocks the biological activity of IL-17A/F and IL-17E signaling through this receptor. It has been approved for the treatment of moderate to severe plaque psoriasis (phase 3 comparative trials) ${ }^{65}$.

Targeting IL-17A has become the focus of preclinical studies in other types of cancer. For example, the administration of AIN457 / secukinumab (see table 1) to mice carrying human myeloma reduced bone damage and significantly inhibited tumor growth compared to isotype-administered control mice ${ }^{66}$. Similarly, the treatment of mice bearing breast cancer with anti-IL-17A antibodies decreased the production of programmed death ligand 1 (PDL1) in the tumor microenvironment, promoted the secretion of Interferon gamma by $\mathrm{CD}^{+}$and $\mathrm{CD}^{+} \mathrm{T}$ cells, and decreased the tumor infiltration by regulatory $\mathrm{T}$ cells, thereby, anti-IL-17A enhances the adaptive immune response in the tumor microenvironment ${ }^{67}$. 


$$
\text { 昜 }
$$


Table 1. Pharmaceutical pipeline of monoclonal antibodies and bispecific antibodies targeting IL-17/IL-17RA axis. Abbreviations: INN, International Nonproprietary Names; RA, rheumatoid arthritis; PSA, psoriatic arthritis; SA, spondyloarthritis; Pso, psoriasis; MS, multiple sclerosis; COPD, chronic obstructive pulmonary disease; TNFa: tumor necrosis factor alpha.

\section{CONCLUSION}

Angiogenesis is a complex process in which lots of actors take part. Normalizing tumor vessels or inducing tumor regression remains a challenging task in all cancer types. Therapeutic schedules including monoclonal antibodies associated with chemotherapy backbone lead most of the time to mechanisms of resistance and tumor escape. Thus the development of combined strategies, associated with relevant biomarkers of response, is of high priority. IL-17A/IL-17RA axis is a promising target but the mechanisms of action in CRC are not fully understood and need further consideration. In this context, targeting IL-17/IL17RA axis in mCRC along with VEGF pathway could represent a non-negligible alternative to explore in future clinical trials.

\section{DISCLOSURE}

Gilles Paintaud reports grants from Novartis, Roche Pharma, Genzyme, MSD, Servier and Pfizer.

\section{REFERENCES}

1. Bossard N, Velten M, Remontet L, et al. Survival of cancer patients in France: a populationbased study from The Association of the French Cancer Registries (FRANCIM). Eur J Cancer. 2007;43(1):149-160. doi:10.1016/j.ejca.2006.07.021.

2. Jooste $\mathrm{V}$, Remontet $\mathrm{L}$, Colonna $\mathrm{M}$, et al. Trends in the incidence of digestive cancers in France between 1980 and 2005 and projections for the year 2010. Eur J Cancer Prev. 2011;20(5):375380. doi:10.1097/CEJ.0b013e3283465426.

3. Favoriti P, Carbone G, Greco M, Pirozzi F, Pirozzi REM, Corcione F. Worldwide burden of colorectal cancer: a review. Updates Surg. 2016;68(1):7-11. doi:10.1007/s13304-016-0359-y. 
4. Sanz-Garcia E, Grasselli J, Argiles G, Elez ME, Tabernero J. Current and advancing treatments for metastatic colorectal cancer. Expert Opin Biol Ther. 2016;16(1):93-110. doi:10.1517/14712598.2016.1108405.

5. Boehm T, Folkman J, Browder T, O'Reilly MS. Antiangiogenic therapy of experimental cancer does not induce acquired drug resistance. Nature. 1997;390(6658):404-407. doi:10.1038/37126.

6. Kieran MW, Kalluri R, Cho Y-J. The VEGF pathway in cancer and disease: responses, resistance, and the path forward. Cold Spring Harb Perspect Med. 2012;2(12):a006593. doi:10.1101/cshperspect.a006593.

7. Mirone G, Shukla A, Marfe G. Signaling mechanisms of resistance to EGFR- and AntiAngiogenic Inhibitors cancer. Crit Rev Oncol Hematol. 2016;97:85-95. doi:10.1016/j.critrevonc.2015.08.012.

8. Tejpar S, Prenen H, Mazzone M. Overcoming resistance to antiangiogenic therapies. Oncologist. 2012;17(8):1039-1050. doi:10.1634/theoncologist.2012-0068.

9. Fan F, Samuel S, Gaur P, et al. Chronic exposure of colorectal cancer cells to bevacizumab promotes compensatory pathways that mediate tumour cell migration. $\mathrm{Br} J$ Cancer. 2011;104(8):1270-1277. doi:10.1038/bjc.2011.81.

10. Yamagishi N, Teshima-Kondo S, Masuda K, et al. Chronic inhibition of tumor cell-derived VEGF enhances the malignant phenotype of colorectal cancer cells. BMC Cancer. 2013;13:229. doi:10.1186/1471-2407-13-229.

11. Mésange $P$, Poindessous V, Sabbah M, Escargueil AE, de Gramont A, Larsen AK. Intrinsic bevacizumab resistance is associated with prolonged activation of autocrine VEGF signaling and hypoxia tolerance in colorectal cancer cells and can be overcome by nintedanib, a small molecule angiokinase inhibitor. Oncotarget. 2014;5(13):4709-4721. doi:10.18632/oncotarget.1671.

12. Gaffen SL, Jain R, Garg A V, Cua DJ. The IL-23-IL-17 immune axis: from mechanisms to therapeutic testing. Nat Rev Immunol. 2014;14(9):585-600. doi:10.1038/nri3707.

13. Ouyang $\mathrm{W}$, Kolls JK, Zheng $\mathrm{Y}$. The biological functions of $\mathrm{T}$ helper 17 cell effector cytokines in inflammation. Immunity. 2008;28(4):454-467. doi:S1074-7613(08)00119-2 [pii]10.1016/j.immuni.2008.03.004.

14. Steinman L. A brief history of $T(H) 17$, the first major revision in the $T(H) 1 / T(H) 2$ hypothesis of T cell-mediated tissue damage. Nat Med. 2007;13(2):139-145. doi:nm1551 
[pii]10.1038/nm1551.

15. Yang B, Kang H, Fung A, Zhao H, Wang $T$, Ma D. The role of interleukin 17 in tumour proliferation, angiogenesis, and metastasis. Mediators Inflamm. 2014;2014:623759. doi:10.1155/2014/623759.

16. Zou W, Restifo NP. T(H)17 cells in tumour immunity and immunotherapy. Nat Rev Immunol. 2010;10(4):248-256. doi:10.1038/nri2742.

17. Miossec P, Kolls JK. Targeting IL-17 and TH17 cells in chronic inflammation. Nat Rev Drug Discov. 2012;11(10):763-776. doi:nrd3794 [pii]10.1038/nrd3794.

18. Murugaiyan G, Saha B. Protumor vs antitumor functions of IL-17. J Immunol. 2009;183(7):4169-4175. doi:10.4049/jimmunol.0901017.

19. Iwakura $Y$, Ishigame H, Saijo S, Nakae S. Functional specialization of interleukin-17 family members. Immunity. 2011;34(2):149-162. doi:10.1016/j.immuni.2011.02.012.

20. Hirota K, Ahlfors H, Duarte JH, Stockinger B. Regulation and function of innate and adaptive interleukin-17-producing cells. EMBO Rep. 2011;13(2):113-120. doi:embor2011248 [pii]10.1038/embor.2011.248.

21. Chang SH, Dong C. IL-17F: regulation, signaling and function in inflammation. Cytokine. 2009;46(1):7-11. doi:10.1016/j.cyto.2008.12.024.

22. Le Gouvello S, Bastuji-Garin S, Aloulou N, et al. High prevalence of Foxp3 and IL17 in MMRproficient colorectal carcinomas. Gut. 2008;57(6):772-779. doi:10.1136/gut.2007.123794.

23. Georgiades IB, Curtis LJ, Morris RM, Bird CC, Wyllie AH. Heterogeneity studies identify a subset of sporadic colorectal cancers without evidence for chromosomal or microsatellite instability. Oncogene. 2000;18(56):7933-7940. doi:10.1038/sj.onc.1203368.

24. Tang R, Changchien CR, Wu M-C, et al. Colorectal cancer without high microsatellite instability and chromosomal instability--an alternative genetic pathway to human colorectal cancer. Carcinogenesis. 2003;25(5):841-846. doi:10.1093/carcin/bgh074.

25. Cui GL, Yuan AP, Goll R, Florholmen J. IL-17A in the tumor microenvironment of the human colorectal adenoma-carcinoma sequence. Scand J Gastroenterol. 2012;47(11):1304-1312. doi:10.3109/00365521.2012.725089.

26. Liu J, Duan Y, Cheng X, et al. IL-17 is associated with poor prognosis and promotes angiogenesis via stimulating VEGF production of cancer cells in colorectal carcinoma. Biochem Biophys Res Commun. 2011;407(2):348-354. doi:10.1016/j.bbrc.2011.03.021. 
27. Radosavljevic G, Ljujic B, Jovanovic I, et al. Interleukin-17 may be a valuable serum tumor marker in patients with colorectal carcinoma. Neoplasma. 2010;57(2):135-144.

http://www.ncbi.nlm.nih.gov/entrez/query.fcgi?cmd=Retrieve\&db=PubMed\&dopt=Citation\&l ist_uids $=20099977$.

28. Wang J, Xu K, Wu J, et al. The changes of Th17 cells and the related cytokines in the progression of human colorectal cancers. BMC Cancer. 2012;12:418. doi:1471-2407-12-418 [pii]10.1186/1471-2407-12-418.

29. Lereclus E, Tout M, Girault A, et al. A possible association of baseline serum IL-17A concentrations with progression-free survival of metastatic colorectal cancer patients treated with a bevacizumab-based regimen. BMC Cancer. 2017. doi:10.1186/s12885-017-3210-z.

30. Tosolini M, Kirilovsky A, Mlecnik B, et al. Clinical Impact of Different Classes of Infiltrating T Cytotoxic and Helper Cells (Th1, Th2, Treg, Th17) in Patients with Colorectal Cancer. Cancer Res. 2011;71(4):1263-1271. doi:10.1158/0008-5472.CAN-10-2907.

31. Housseau F, Wu S, Wick EC, et al. Microenvironment and Immunology Redundant Innate and Adaptive Sources of IL17 Production Drive Colon Tumorigenesis. doi:10.1158/0008-5472.CAN15-0749.

32. Tseng JY, Yang CY, Liang SC, et al. Interleukin-17A Modulates Circulating Tumor Cells in Tumor Draining Vein of Colorectal Cancers and Affects Metastases. Clin Cancer Res. 2014;20(11):2885-2897. doi:10.1158/1078-0432.ccr-13-2162.

33. Wang K, Kim MKK, Di Caro G, et al. Interleukin-17 receptor a signaling in transformed enterocytes promotes early colorectal tumorigenesis. Immunity. 2014;41(6):1052-1063. doi:10.1016/j.immuni.2014.11.009.

34. Chung AS, Wu XM, Zhuang GL, et al. An interleukin-17-mediated paracrine network promotes tumor resistance to anti-angiogenic therapy. Nat Med. 2013;19(9):1114-1123. doi:10.1038/nm.3291.

35. Zhao Y, Wu T, Shao S, Shi B, Zhao Y. Phenotype, development, and biological function of myeloid-derived suppressor cells. Oncoimmunology. 2016;5(2):e1004983. doi:10.1080/2162402X.2015.1004983.

36. Manjili MH, Wang X-Y, Abrams S. Evolution of Our Understanding of Myeloid Regulatory Cells: From MDSCs to Mregs. Front Immunol. 2014;5:303. doi:10.3389/fimmu.2014.00303.

37. Obermajer N, Wong JL, Edwards RP, et al. Induction and stability of human Th17 cells require endogenous NOS2 and cGMP-dependent NO signaling. J Exp Med. 2013;210(7):1433-1445. 
doi:10.1084/jem.20121277.

38. Xie Z, Qu Y, leng $Y$, et al. human colon carcinogenesis is associated with increased interleukin17-driven inflammatory responses. Drug Des Devel Ther. 2015;(9):1679-1689. doi:10.2147/DDDT.S79431.

39. Wang L, Yi T, Kortylewski M, Pardoll DM, Zeng D, Yu H. IL-17 can promote tumor growth through an IL-6-Stat3 signaling pathway. J Exp Med. 2009;206(7):1457-1464. doi:10.1084/jem.20090207.

40. Numasaki M, Fukushi J, Ono $\mathrm{M}$, et al. Interleukin-17 promotes angiogenesis and tumor growth. Blood. 2003;101(7):2620-2627. doi:10.1182/blood-2002-05-1461.

41. Anh DT Van, Park SM, Lee H, et al. The Membrane-Bound Form of IL-17A Promotes the Growth and Tumorigenicity of Colon Cancer. Mol Cells. 2016;39(7):536-542. doi:10.14348/molcells.2016.0048.

42. Chen J, Xia J, Liang X, et al. Intratumoral expression of IL-17 and its prognostic role in gastric adenocarcinoma patients. Int J Biol Sci. 2011;7(1):53-60.

http://www.ncbi.nlm.nih.gov/pubmed/21234303. Accessed March 21, 2017.

43. Kryczek I, Wei S, Szeliga W, Vatan L, Zou W. Endogenous IL-17 contributes to reduced tumor growth and metastasis. Blood. 2009;114(2):357-359. doi:10.1182/blood-2008-09-177360.

44. Qian X, Chen H, Wu X, Hu L, Huang Q, Jin Y. Interleukin-17 acts as double-edged sword in antitumor immunity and tumorigenesis. Cytokine. 2016. doi:10.1016/j.cyto.2015.09.011.

45. De Simone V, Pallone F, Monteleone G, Stolfi C. Role of TH17 cytokines in the control of colorectal cancer. Oncoimmunology. 2013;2(12):e26617. doi:10.4161/onci.26617.

46. Tong Z, Yang XO, Yan H, et al. A Protective Role by Interleukin-17F in Colon Tumorigenesis. Katoh M, ed. PLoS One. 2012;7(4):e34959. doi:10.1371/journal.pone.0034959.

47. Ye J, Livergood RS, Peng G. The Role and Regulation of Human Th17 Cells in Tumor Immunity. Am J Pathol. 2013;182(1):10-20. doi:10.1016/j.ajpath.2012.08.041.

48. McGovern DPB, Rotter JI, Mei L, et al. Genetic epistasis of IL23/IL17 pathway genes in Crohn's disease. Inflamm Bowel Dis. 2009;15(6):883-889. doi:10.1002/ibd.20855.

49. Hayashi R, Tahara T, Shiroeda H, et al. Influence of IL17A polymorphisms (rs2275913 and rs3748067) on the susceptibility to ulcerative colitis. Clin Exp Med. 2013;13(4):239-244. doi:10.1007/s10238-012-0206-5.

50. Eaden JA, Abrams KR, Mayberry JF. The risk of colorectal cancer in ulcerative colitis: a meta- 
analysis. Gut. 2001;48(4):526-535. doi:10.1136/GUT.48.4.526.

51. Liu XK, Lin X, Gaffen SL. Crucial role for nuclear factor of activated T cells in T cell receptormediated regulation of human interleukin-17. J Biol Chem. 2004;279(50):52762-52771. doi:10.1074/jbc.M405764200.

52. Kawaguchi M, Takahashi D, Hizawa N, et al. IL-17F sequence variant (His161Arg) is associated with protection against asthma and antagonizes wild-type IL-17F activity. J Allergy Clin Immunol. 2006;117(4):795-801. doi:10.1016/j.jaci.2005.12.1346.

53. Duan Y, Shi J-NN, Pan C, Chen H-LL, Zhang S-ZZ. Association between the interleukin-17A 197G >A (rs2275913) polymorphism and risk of digestive cancer. Asian Pac J Cancer Prev. 2014;15(21):9295-9300. http://www.ncbi.nlm.nih.gov/pubmed/25422215. Accessed December 7, 2016.

54. Rafiei A, Hosseini V, Janbabai G, et al. Polymorphism in the interleukin-17A promoter contributes to gastric cancer. World J Gastroenterol. 2013;19(34):5693-5699. doi:10.3748/wjg.v19.i34.5693.

55. Wu X, Zeng Z, Chen B, et al. Association between polymorphisms in interleukin-17A and interleukin-17F genes and risks of gastric cancer. Int J Cancer. 2010;127(1):86-92. doi:10.1002/ijc.25027.

56. Zhang XX, Zheng L, Sun Y, Zhang XX. Analysis of the association of interleukin-17 gene polymorphisms with gastric cancer risk and interaction with Helicobacter pylori infection in a Chinese population. Tumour Biol. 2014;35(2):1575-1580. doi:10.1007/s13277-013-1217-x.

57. Dai ZM, Zhang TS, Lin S, et al. Role of IL-17A rs2275913 and IL-17F rs763780 polymorphisms in risk of cancer development: an updated meta-analysis. Sci Rep. 2016;6:20439. doi:10.1038/srep20439.

58. Nemati K, Golmoghaddam H, Hosseini S V, Ghaderi A, Doroudchi M. Interleukin-17FT7488 allele is associated with a decreased risk of colorectal cancer and tumor progression. Gene. 2015;561(1):88-94. doi:10.1016/j.gene.2015.02.014.

59. Omrane I, Marrakchi R, Baroudi O, et al. Significant association between interleukin-17A polymorphism and colorectal cancer. Tumour Biol. 2014;35(7):6627-6632. doi:10.1007/s13277-014-1890-4.

60. Lu Y, Gu J, Lu H, et al. Association Between IL-17A +197 G/A Polymorphism and Cancer Risk: A Meta-Analysis. Genet Test Mol Biomarkers. 2016;20(1):24-30. doi:10.1089/gtmb.2015.0143.

61. Lowes MA, Bowcock AM, Krueger JG. Pathogenesis and therapy of psoriasis. Nature. 
2007;445(7130):866-873. doi:10.1038/nature05663.

62. Chao C-C, Chen S-J, Adamopoulos IE, et al. Anti-IL-17A therapy protects against bone erosion in experimental models of rheumatoid arthritis. Autoimmunity. 2011;44(3):243-252. doi:10.3109/08916934.2010.517815.

63. Hueber W, Patel DD, Dryja T, et al. Effects of AIN457, a fully human antibody to interleukin17A, on psoriasis, rheumatoid arthritis, and uveitis. Sci Trans/ Med. 2010;2(52):52ra72. doi:10.1126/scitranslmed.3001107.

64. Gordon KB, Blauvelt A, Papp KA, et al. Phase 3 Trials of Ixekizumab in Moderate-to-Severe Plaque Psoriasis. N Engl J Med. 2016;375(4):345-356. doi:10.1056/NEJMoa1512711.

65. Lebwohl M, Strober B, Menter A, et al. Phase 3 Studies Comparing Brodalumab with Ustekinumab in Psoriasis. N EnglJ Med. 2015;373(14):1318-1328. doi:10.1056/NEJMoa1503824.

66. Prabhala RH, Fulciniti M, Pelluru D, et al. Targeting IL-17A in Multiple Myeloma: A Potential Novel Therapeutic Approach in Myeloma HHS Public Access. Leukemia. 2016;30(2):379-389. doi:10.1038/leu.2015.228.

67. Ma Y-F, Chen C, Li D, et al. Targeting of interleukin (IL)-17A inhibits PDL1 expression in tumor cells and induces anticancer immunity in an estrogen receptor-negative murine model of breast cancer. Oncotarget. December 2016. doi:10.18632/oncotarget.13819. 